Lowery, Gray, Monogan

The Construction of Interest Communities: Distinguishing Bottom-Up and Top-Down Models

\author{
David Lowery, Professor \\ Departement Bestuurkunde \\ Wassenaarseweg 52 \\ P.O. Box 9555, Pieter de la Court Gebouw \\ Universiteit Leiden \\ 2300 RB Leiden, Nederland \\ dlowery@fsw.leidenuniv.nl
Virginia Gray, Robert Watson Winston Distinguished Professor
Department of Political Science
University of North Carolina at Chapel Hill
Chapel Hill, NC 27599 USA
vagray@email.unc.edu
James Monogan, Ph.D. Candidate
Department of Political Science
University of North Carolina at Chapel Hill
Chapel Hill, NC 27599 USA
monogan@email.unc.edu

An earlier version of this paper was delivered at the 2006 Annual Meeting of the Midwest

Political Science Association, Chicago, Illinois, April. This research was supported by a Robert

Wood Johnson Foundation Investigator Award in Health Policy Research (ID\#047727). We

thank Jennifer Wolak for coding the health sector interest group data. 
Lowery, Gray, Monogan

\begin{abstract}
Two theories are now used to explain the size and composition of interest communities: Olson's $(1965 ; 1982)$ bottom-up collective action model and Gray and Lowery's top-down ESA model. Unfortunately, one of the common ways of testing these models - aggregate-level analyses of interest populations - cannot easily distinguish between them. Empirical evidence supporting one model will almost inevitably support the other. We explain why this is so, illustrating the problem with data on state populations of health interest organizations. We also discuss how the two models might be better distinguished.
\end{abstract}




\section{The Construction of Interest Communities: Distinguishing Bottom-Up and Top-Down Models}

At one time, the construction of interest communities was not viewed as perplexing. In Truman's (1951) view, individuals naturally come together to pursue collective interests. The resulting population of lobby organizations might be large or small depending on the number of policy concerns driving joining and it might be biased with respect to the distribution of interests in society. But interest system size and bias would reflect the pattern of disturbances motivating individuals to join. This straightforward understanding of the construction of interest systems has now been replaced by two competing models. The first is Olson's (1965) model of collective action in which rational economic calculation by individuals determines the mobilization of lobby organizations, which then accumulate in a fashion that is essentially unconstrained by other organizations. The interesting action in this model is at the bottom of the process - individual decisions leading to mobilization events. In contrast, Gray and Lowery's (1996a) energy, stability, area (ESA) model highlights the role of environmental resources in constraining the size of interest populations. ${ }^{1}$ These topdown constraints are viewed as so severe as to more proximally determine the size and composition of interest systems.

These competing perspectives have profoundly different implications for how we understand the nature of interest system bias, the linkage of individual member

\footnotetext{
${ }^{1}$ This view is more consistent with sociological approaches to organizational theory. Key works include Aldrich and Pfeffer (1976), Hannan and Freeman (1989), and Pfeffer and Salancik (1978).
} 
Lowery, Gray, Monogan

preferences and lobbying objectives, the ultimate size of interest systems, and their consequences for public policy. This suggests that we need to distinguish which of the two models provides a more valid enumeration of the construction rules governing interest communities. Unfortunately, one of the common ways in which both models are tested-aggregate-level analyses of interest populations - cannot easily distinguish between then. Empirical evidence supporting one will inevitably support the other. We examine this problem by first explaining this equivalence. We then illustrate the problem with data on state populations of health interest organizations. We also discuss how the two models might be better distinguished using both aggregate- and more micro-level data on organized interests. Finally, we discuss why these results suggest that past aggregate analyses using an Olsonian framework may need to be reconsidered.

\section{Distinguishing the Two Models}

In Truman's model, neither the individuals who join interest organizations nor the organizations themselves were seriously constrained by environmental forces. Truman (1951, 156-87), of course, did assume that the policy positions espoused by organized interests are constrained toward moderation by their need to satisfy the heterogeneous preferences of members who might also join other organized interests. And how well leaders manage distributions of members' preferences might well influence an organization's survival prospects and, thereby, the size and composition of interest communities (Truman 1951, 188-211). But these constraints arise from the internal distributions of preferences within membership organizations. Truman did not imagine beyond a secondary role for counter-disturbances - that forces beyond the intersection of policy disturbances and individual interests might limit innate proclivities to join. 
In this regard, Olson's (1965) model share much with Truman's. In both, individual preferences constitute the basic motivation for group formation and variations in how these preferences are reflected in patterns of mobilization constitute the key explanatory problem. In both, the aggregation of interest organizations into interest communities is but an epiphenomenon arising from individual choices (Powell and DiMaggio 1991, 2). Olson departed radically from Truman, however, by weighing policy preferences as a motive for joining with a calculation of its opportunity cost. Incentives to free ride on the political activity of others are ubiquitous, but their import varies in two ways (Olson 1965, 53-64). The first lies in the balance of collective and private goods that are the focus of policy preferences. If the latter prevails, then free riding is not possible and Truman's expectation of a natural link between preferences, disturbances, and mobilization should obtain. Incentives to free ride should also vary by the size of the referent community of fellow participants, a contextual factor that is independent of preferences per se. If there a few potential members of a group - whether individuals in a membership group, institutions considering forming a trade association, or individual institutions contemplating lobbying directly for collective goods - then the likelihood of free riding declines.

If Olson's analysis stopped at this point, the epiphenomenon of lobbying communities would be expected to be uniformly small and highly biased toward organizations seeking private goods and only small groups seeking collective goods. But Olson $(1965,132-167)$ went on to consider the relationship of inducements and contributions, ${ }^{2}$ arguing that if incentives to free ride undermine the mobilization of large

\footnotetext{
${ }^{2}$ And surprisingly, given its role as a foundational analysis underlying the ESA model,
} 
Lowery, Gray, Monogan

groups, then entrepreneurs can offer selective incentives as side payments to induce participation. Olson $(1982,40)$ also asserted that interest organizations rarely die once having overcome the initial barriers to mobilization via selective incentives:

"Organizations with selective incentives in stable societies normally survive indefinitely." When coupled with a further assumption that the potential supply of selective benefits is unlimited with no declining marginal utility, this implies that interest populations are essentially unlimited.

In sum, Olson's model is a bottom-up view of the construction of interest communities. The critical action takes place at the level of the member. Their preferences for collective action are surely real. But their pursuit is influenced by the number of other individuals who might join an organization or other organizations that might engage in political activity. These numbers define the severity of the collective action problem faced by organizations. Interest organization populations, in this interpretation, are artifacts in that they are the products of the severity of the collective action problem within different populations of members. Interest communities are thus constructed from the bottom up as interest organizations solve over time their respective collective action problems. But once having solved its own collective action problem, each organization has no real bearing on the vitality rates of others in the community.

Gray and Lowery's (1996a) ESA model of interest community density is largely agnostic about the individual-level mobilization, working equally well with either a basic Trumanesque or Olsonian view of individual mobilization. But in explaining interest

this notion was also incorporated as a central theme in resource dependence theory (Pfeffer and Salancik 1978). 
communities, the ESA model is top-down in orientation in emphasizing environmental constraints, not individual-level motivations. Thus, the key variable determining vital rates of interest organizations is the presence of other interest organizations potentially representing the same interests. This variable is the area term of the ESA model, which is usually interpreted as the potential number of constituents in the interest domain that might be represented by an interest organization. The main effect of this variable is positive; we should observe more organizations when we observe more potential constituents. But this relationship is expected to be progressively less positive so that growth rates decline as numbers of potential constituents increase. This reflects density dependence or crowding as similar organizations competitively exclude each other from ever finer representation of interests and the resources needed for organizational maintenance. At some point, quite simply, there is a declining marginal return from ever more fine-grained representation of interests and reliance on ever narrower resource bases. As a result, and in sharp contrast to Olson's expectations, the birth rates of new organizations should decline and/or the death rates of older organizations should increase as interest communities become more crowded (Gray and Lowery 2001; Nownes 2004; Nownes and Lipinski 2005).

The other terms of the ESA model reflect, respectively, insights from Truman and Olson. Energy refers to the policy issues of concern to lobbying organization and the level of uncertainty about their resolution that are used to stimulate mobilization. These are typically measured by the size of political agenda in a given policy area and level of party competition, respectively (Gray, Lowery, Fellowes, and Anderson 2005; Lowery, Gray, Fellowes, and Anderson 2004; Brasher, Lowery, and Gray 1999; Lowery 2007). 
Thus, the energy term of the model reflects Truman's (1951) notion that policy disturbances promote mobilization. In the ESA model, however, this is a more secondary determinant that raises or lowers the more important density response function with respect to number of constituents. The stability term of the model draws on Olson's insight that interest communities must be largely reconstructed from scratch after profound changes in political regimes such as after devastating wars. ${ }^{3}$ But while Olson (1982) viewed such processes as occurring over a century or so, ESA empirical analyses have found that interest systems reach equilibrium or their carrying capacity for interest organizations far more quickly. Thus, while the stability term is of theoretical interest, it does not have empirical import in stable democracies.

The ESA model of interest system density thus emphasizes top-down processes in which number of potential constituents sets in a density dependent manner the basic carrying capacity of political systems for organized interests. ${ }^{4}$ This density dependent response function may be lowered or raised by the size of the political agenda and the level of uncertainly associated with different levels of party competition. But overall, interest systems are self-limiting as crowding suppresses birth rates and enhances death rates within guilds of organized interests. Another implication of the model that will

\footnotetext{
${ }^{3}$ Or more precisely, both insights draw from population biology's analysis of changes in bio-diversity following devastating environmental events such as volcanic eruptions. ${ }^{4}$ Or, perhaps it might be better to say that population pressures and constraints in the ESA model are lateral in nature in that crowding among similar or related organizations and fixed resources in the environment work together to limit the size of interest populations.
} 
become important later arises from its assumption that the density dependent response functions of different guilds vary and the observation that the content of policy agendas change over time. That is, given differences in the heterogeneity of issues within interest guilds and variations in average capacities across guilds to organize, density dependent mobilization rates will vary across guilds. In contrast to conventional interpretation of bias in interest communities (Schattschneider 1960; Schlozman and Tierney 1986), then, the diversity of interest communities is complexly related to the distribution of interests in society (Lowery and Gray 2004a; Lowery, Gray, and Fellowes 2004).

The Olson and ESA models suggest a number of test implications at individualand aggregate-levels, test implications that scholars have not been shy to exploit. Both levels of analysis are important. But for those interested in the overall size and growth of interest systems, bias in interest communities, and its consequences for public policy, aggregate-level tests are especially interesting. But here is where our problem arises. That is, the models typically used to test the aggregate implications of the Olson and ESA models cannot easily distinguish between them. Results that are supportive of one model will be equally supportive of the other.

To see this, consider first the typical aggregate-level test of Olson's hypothesis (e.g., Andres 1985; Bois 1989; Grier, Munger, and Roberts 1991; 1994; Masters and Keim 1985; McKeown 1994; Humphries 1991; Mitchell, Hansen, and Jepsen 1997; Hansen and Mitchell 2000; Lowery, Gray, Anderson, and Newmark 2004), ${ }^{5}$ which can be

\footnotetext{
${ }^{5}$ Most of this work has been done on PACs. Unfortunately, PACs are a remarkably inappropriate venue in which to test either hypothesis given that the theory speak to mobilization to lobby, not the frequency of use of a specific lobbying tool, such as
} 
Lowery, Gray, Monogan

expressed as follows:

$$
\text { Eq1: }(L R / P L R)=\square-\square{ }_{1} P L R
$$

where LR is the number of lobby registrations actually observed and PLR is the number of potential lobby registrations or the full population from which actual registrations are drawn. ${ }^{6}$ The ratio of LR and PLR is lobbying rate or the proportion of institutions of a given type (industry or jurisdiction, typically) that actually choose to lobby. As indicated by the negatively signed slope coefficient, lobbying rate is expected to decline as the number of institutions that might lobby increases. In short, the severity of the collective action problem should increase with the number of organizations that might lobby, which Olson suggests should lead to free riding or a declining proportion of potential lobbying organization actually opting to lobby.

Now, consider the comparable basic ESA model used in aggregate-level tests

political action committees (Gray and Lowery 1997a). This may account for the traditionally weak and inconsistent results on the collective action hypothesis in this literature. Even so, equation 1, is a rather extreme simplification of the models used in these analyses. That is, most were designed to test a range of hypotheses, most of which go beyond our concerns.

${ }^{6}$ Some studies - PAC studies especially - tend to use a variant of this model where individual firms are the unit of analysis (rather than industries, states, or a combination of the two) and the dependent variable is the firm's decision to lobby or not lobby or to have or not have a PAC. These models then include measures of the size of the industries/states to test the collective action hypothesis. These models are functionally organizational-level equivalents of the model identified in equation 1. 
Lowery, Gray, Monogan

(Gray and Lowery 1996a; Lowery and Gray 1995; Gray, Lowery, Fellowes, and Anderson 2005; Lowery, Gray, Fellowes, and Anderson 2004). Ignoring the complication of density dependence for now, the core element of the ESA model can be represented as:

$$
\text { Eq.2: } L R=\square+\square_{1} P L R
$$

where LR is again the number of lobby registrations and PLR is the number of potential lobby registrations. The positive slope coefficient suggests that the number of organizations actually lobbying is positively related to the number of potential lobbying organizations.

Obviously, the numerator in the stripped-down Olson equation is the dependent variable in the short version of the ESA model. More importantly, both employ the same independent variable: the potential number of organization lobby registrants. If both dependent variables have, as expected, a strong relationship with that independent variable, they will be related to each other, if only in a spurious fashion. This relationship, however, becomes more than spurious once we consider their shared independent variable: the number of organizations that could potentially lobby. Indeed, any two of these three variables define an accounting identity. If the size of the potential lobbying population and number of lobbying registrations are known, we can calculate lobbying participation rate. Conversely, given the lobby participation rate and the size of the potential lobbying population, we can calculate how many organizations are registered to lobby. And more to the point, if the slope coefficient of the ESA model in equation 2 is greater than zero and less than one, the same data will always produce results that would be consistent with the Olson model's expectation of a negative 
estimate in equation 1. And such expectations are quite reasonable. ${ }^{7}$ The ESA hypothesis posits that the slope coefficient in equation 1 should be greater than zero. And while the ESA model does not strictly require that the number of lobby organizations should increase at a slower rate than the number of potential organizations that might lobby, this expectation is strongly implied by the density dependence hypothesis. ${ }^{8}$

We will demonstrate this last relationship empirically below. In a strict sense, of course, such a demonstration is unnecessary since they are logical or mathematical in character. Still, we will see that empirical tests point toward some indirect means of distinguishing the two models. In conducting these tests, however, we use somewhat more elaborate version of the two models:

$$
\begin{gathered}
\text { Eq. 3: }(L R / P L R)=\square-\square_{1} P L R+\square_{2} P L R^{2}+\square_{3} P C+\square_{4} P A \text {, and } \\
\text { Eq. 4: } L R=\square+\square_{1} P L R-\square_{2} P L R^{2}+\square_{3} P C+\square_{4} P A
\end{gathered}
$$

where LR and PLR are again number of lobby registrations and number of potential registrations. We have added to both models measures of the level of party competition (PC) and the size of the policy agenda of interest to the interest guilds (PA) to reflect the energy term of the ESA model. These are key parts of the ESA model. Adding them to the collective action model in equation 3 renders the empirical estimates more

\footnotetext{
${ }^{7}$ Actually, even this condition is too strongly stated. The slope coefficient in equation 2 need only be less than 1.0 for the same data to generate results supportive of an Olson model of the form of equation 2.

${ }^{8}$ Importantly, this expectation is not necessarily true with respect to the use of specific lobbying techniques like the establishment of PACs by organizations that have already opted to lobby given the crowded room hypothesis (see: Gray and Lowery 1997a).
} 
Lowery, Gray, Monogan

comparable and should do no great damage to the Olson model as this essentially entails adding irrelevant explanatory variables to it.

We've also added the squared term of potential number of lobby registrations to both models. The polynomial specification of PLR is essential to test the ESA density dependence hypothesis that growth in registration declines as number of potential registrations increases. The ESA model suggests that the linear term of the model should generate a positive estimate and its squared term a negative estimate. We included this polynomial specification in the Olson model represented by equation 3 for better reasons, however, than merely allowing us to compare the models directly. That is, while most prior aggregate tests of the Olson model examine only the linear impact of potential number of lobby registrants (or the size of the industry) on participation rates, this seems to us an unreasonable specification. Simply put, it suggests that the enhanced incidence of free riding resulting from an increase in the potential number of organizations that might lobby from 999 to 1,000 organizations or individuals will be the same as an increase from 4 to 5. It seems far more plausible, and consistent with Olson's analysis, that the decline in lobby participation rates (LPR) should slow as number of potential organizations that might lobby becomes smaller and organizations thereby become more cognizant of each other.

\section{Empirically Analyzing the Models}

\section{Data and Operationalizations}

We test the models with data on lobby registrations among health interest organizations in the American states. The states provide us with considerable variation in all of the variables specified in both models and thus serve as our unit of analysis. The 
Lowery, Gray, Monogan

dependent variables in the ESA models are the number or density of lobby registrations in the states by health organizations concerned, respectively, with: 1.) direct patient care, 2.) drugs and health products, 3.) health finance, 4.) local government health agencies, 5.) health care advocacy, 6.) health professional associations, and 7.) health education institutions. ${ }^{9}$ We also analyze the total number of health organizations. These eight categories were aggregated upward from an even finer 18 category coding of the substantive interests of health organization lobby registrations. These are reported in the

${ }^{9}$ The state lobby registration data have been described elsewhere (Gray and Lowery 2001). Briefly, lobby registration lists were gathered by mail or web page from state agencies responsible for their maintenance. After purging the lists of state agencies in states requiring their registration, organizations registered to lobby - not individual lobbyists - were coded by organizational type (membership group, institution, or association) and interest content (26 guilds of substantive interests) using directories of organizations and associations and the web pages of organizations. A second coder examined the coding assignments with discrepancies resolved via discussion. Only 1.58 percent of the 35,928 organizational lobby registrations in 1997 could not be coded by type or substantive interest. The organizations in the health category among the complete population of guilds were then recoded by substantive interest using 18 categories reported in appendix 1. Only 38 organizations or 0.66 percent of the 1997 health population could not be coded by these categories of substantive interest. Fortunately, previous work indicates that the stringency of state lobbying registration requirements has little impact on the density (Lowery and Gray 1997; 1994) and diversity (Gray and Lowery 1998) of state interest communities. 
Lowery, Gray, Monogan

JOP Web Appendix associated with this article along with examples of organizations in each category. In the end, we opted for the more highly aggregated seven-fold classification for convenience. ${ }^{10}$ In the Olson models, the dependent variables are lobby participation rates - the ratio of the number of organizations actually registered to lobby to the total number of organizations that potentially might lobby - of the same seven health guilds and the total number of health interest organizations.

The health interest guild is especially appropriate for testing our hypothesis since its seven sub-guilds vary remarkably in size and makeup among themselves as well as across the states. As seen in figure 1, 5,658 organized interests with health concerns registered to lobby in 1997 , for an average of 113.16 registrations. ${ }^{11}$ This is our

${ }^{10}$ The results were essentially the same at both levels of analysis. But seven or eight sets of results are more readily presented than $18 .$. For example, when the 1997 direct patient care model was re-estimated using the seven sub- categories of organizations providing direct patient care, essentially the same results were generated. Six of the seven coefficients of the area or supply variable were signed correctly and significant as were four of the estimates for their squared values. Six of seven party competition estimates were signed correctly and significant, as were four agenda coefficients. While there was some noise associated with employing such a fine level of aggregation where numbers of registrations were very low, the results nonetheless were very consistent with those presented here.

${ }^{11}$ This number is larger than we have previously reported in work analyzing 26 interest guilds and results from our recoding for this project pharmaceutical and drug product manufacturing firms as health rather than manufacturing organizations, and health 


\section{Lowery, Gray, Monogan}

dependent variable in the ESA models. As seen in the first two columns of table 2, 50.14 percent of the health organization registrations in the average state in 1997 were concerned with direct patient care. In the average state, the next largest category was drug and health product organizations, followed by health professional associations and health education institutions, health care advocacy groups, health finance organizations, and local government health groups and agencies.

The populations from which these registrations were drawn were also quite diverse. A measure of the size of such populations is, of course, the area term of the ESA model and both an independent variable and the denominator in the dependent variable of the Olson model. For all but one of our health guilds, the populations from which organized institutions are drawn are institutions such as hospitals, medical schools, doctors' offices and HMOs, pharmaceutical firms, and insurance companies. For these, population size or area is measured by the number of establishments in a state in 1997 associated with the interests of the sub-guild. ${ }^{12}$

There were, however, several exceptions to this strategy. First, as seen in the appendix, the health finance sub-guild includes health plans, health business services, employer health coalition, and insurance organizations. Data on establishments was

insurance firms as health organizations rather than financial, insurance, and real estate organizations. Neither coding scheme is necessarily preferred in any objective sense since they speak to different theoretical purposes.

12 The Census Bureau's NAICS codes used to assign the establishments in a state to each sub-guild are reported in the last column of the appendix. 


\section{Lowery, Gray, Monogan}

available for only the last. Thus, the area or supply terms of the health finance model tap a narrower range of organization activity than many of the others. Second, the Census Bureau did not provide data on government establishments. So, for local government health agency supply, we use the number of general purpose local governments and health special districts in a state. Third, associations of health professionals are founded not on institutions but on individual health professionals such as doctors and nurses. The interest organizations in this sub-guild are true membership groups. For this sub-guild, then, the sizes of the potential populations from which lobbying organizations might be drawn are measured by the number of health professionals in a state in 1998 as reported by the Department of Labor. Fourth, the area term of the health education sub-guild is measured by the number of medical and nursing schools in a state. As seen in figure 2, the lobby registrants representing direct patient care issues are drawn from a very large population - the average state had fully 10,341.66 direct patient care organizations in 1997. This contrast to the smaller average populations from which health education (13.46 institutions), local government (71.40), health finance (63.86), and health advocacy (66.26) lobby organizations were drawn. The average number of drug and health product firms in the states was 288.56.

The dependent variable in the Olson model is participation rate or the ratio of the actual number of lobby registrations by health organizations to the size of the population from which they are drawn. As seen in figure 3, health advocacy organizations had, on average, the highest participation rate with 22.95 percent. The lowest rates were for health professionals. Given that the denominator is measured in hundreds, the participation rate of 0.01 percent reported in figure 3 indicates that the average state had 


\section{Lowery, Gray, Monogan}

one registration by a health professional group per thousand health professionals. The remaining participation rates fall between these two extreme values.

The energy term is represented by party competition and the size of the health policy agenda of substantive concern to potential lobby organizations. As party competition heightens, the likelihood of sudden policy change increases, encouraging both those favored by as well as those disadvantaged by the status quo to become active. We tap this uncertainty with the folded Ranney Index of state party competition (available for 48 states) in 1997. Since this measure is inversely coded, with values near one indicating one-party dominance, negative estimates will indicate that competition promotes mobilization. Gray, Lowery, Fellowes, and Anderson (2005) following the lead of Bowling and Ferguson (2001) and Wilkerson, Feeley, Schiereck, and Sue (2002), measure constituent interest by the size of the agenda of concern to an interest guild as indicated by the number of bills on the topic considered by the legislature. We developed a comparable measure of the size of the health agenda before state legislatures in $1997 .^{13}$

${ }^{13}$ Bill count data was collected from the "State Full Text of Bills" database on Nexis Academic Universe. The database is maintained by LexisNexis, a division of Reed Elsevier Inc, and is available for a fee at http://www.nexis.com. The database contains bill text files of all bills considered by each statehouse in a calendar year with each bill assigned a set of subject codes, providing a separate listing for each revised version of a bill in the database. For example, Alabama House Bill 175, which appropriated $\$ 4,564,831$ to the Department of Public Health in 1997, was listed five times in the database: one entry was the initial version, three were revisions, and the fifth was the enacted bill. Multiple counts are appropriate because the concerns of organized interests 
Lowery, Gray, Monogan

Our measures count the number of bills with a "health" subject code each year. In 1997, the average number of bill counts was 278 , ranging from a low of 17 in Kentucky to a high of 1,409 in California. The same agenda size measure is employed in all sub-guild models.

\section{Initial Findings}

The results in table 1 provide considerable support for Olson's model. The negative estimates for the linear area variable (PLR) are significant in all cases indicating that participation rates decline as the potential size of lobbying communities increases. The squared value of PLR generates uniformly positive estimates and five of eight are significant at the 0.05 level. Within an Olsonian framework, these estimates suggest that free riding declines as numbers of potential lobby organizations declines. This is illustrated in figure 4, which presents the relationship between lobby participation rate in the states among health finance establishments and the numbers of such establishments, while ignoring the effects of the other independent variables. ${ }^{14}$ Lobbying participation falls from 50 percent in states with fewer than 20 or so health finance organizations to less than 10 percent for those with more than 150 such organizations. ${ }^{15}$

about bills should heighten as they move through the legislative process.

${ }^{14}$ Extensive analyses of these and other data suggest that the effects of the area terms of the models are remarkably independent of agenda size and party competition and so can be examined independently. Still, the figures we present on health finance organizations should be viewed as partial and incomplete models that are more useful for illustration than for providing a complete story.

${ }^{15}$ Similar figures have been constructed for all of the sub-guilds. All are remarkably 


\section{Lowery, Gray, Monogan}

The results for the energy terms of the model are more mixed. All but one of the party dominance estimates generated negative estimates, indicating that participation rates decline as party competition falls. Still, only six of the estimates are discernibly different from zero. And only one agenda size coefficient (for health finance organizations) is positive and significant, which suggests that the size of the issue agenda before legislatures has little to do with lobbying participation rates. Overall, then, these results can certainly be interpreted as supporting the Olson model; size of the potential lobbying community matters, but not much else.

Yet, much the same can be said for the ESA model as seen in Table 2. The dependent variable is the raw number of lobby registrations. In this case, six of the area or LR estimates generated the expected positive and significant estimates while five of the squared LR estimates generated the expected negative and significant estimates. In fact, all of the former would have produced positive, significant estimates had the squared variable been excluded. This suggests that while registrations increase with the density of the population from which lobby groups are drawn, this relationship is only weakly density dependent for the small local government and health education guilds. This will become important later when we compare the two models. For now though, it seems as if the core area element of the ESA model is supported by these results. This is illustrated in figure 5 which presents the relationship between total registrations by health finance organizations in the states and their numbers of such establishments while again ignoring the other independent variables. ${ }^{16}$ Lobby registrations increases from under 10

alike.

${ }^{16}$ Again, similar figures have been constructed for all of the other sub-guilds and all are 
Lowery, Gray, Monogan

in states with very few health finance establishments to 20 or more for states with 300 such organizations. Further, the rate of increase in registrations visibly declines as number of establishments increases.

Table 2 also provides support for the ESA energy hypothesis with the party dominance estimates having the expected negative and significant estimates in all but one case. Registrations are higher in states with more competitive parties. And in sharp contrast to the Olson results, seven of the eight estimates for agenda size (all but the estimate for the local government model) are positive and significant, indicating that number of registrations increases as the size of the health policy agenda being considered by state legislatures grows.

\section{Interpreting the Results}

We have, then, two sets of closely related results that seem to support two distinct theories about the construction of interest systems. The two models are, of course, account for variance in somewhat different dependent variables - lobbying participation rates and total numbers of lobby registrations. It would be very nice if in a spirit of scholarly reconciliation we could combine the models so that all flowers could bloom. Unfortunately, we cannot do so for three reasons. The first and most telling reason is that the two dependent variables and their shared independent variable define, as noted earlier, an accounting identity. If the size of the potential lobby population and number of lobby registrations are determined, we will know by calculation the lobbying participation rate. Conversely, if we know the rate of lobby participation and the size of

remarkably similar, especially so since this is one of our more problematic guilds in terms of the squared term. 


\section{Lowery, Gray, Monogan}

the potential lobby population, we can calculate the number of lobby registrations. By definition, then, one or the other dependent variable is an artifact of the process generating the other. Thus, we cannot be agnostic about which process truly merits explication.

Second, and somewhat counter-intuitively given what has just been said, it is also true that once we go beyond their theoretical relationship, the information captured empirically by the relationship of the Olson dependent variable and the size of the potential lobby population cannot be easily substituted for knowledge about the relationship of the ESA dependent variable and the size of the potential lobby population. Figures 6 and 7 illustrate why this is so. Figure 6 presents the relationship between the predicted values generated from figures 4 and 5, our simplified Olson and ESA models for the health finance guild. As is readily apparent, there is a very strong relationship (Rsquare $=0.97) .{ }^{17}$ Indeed, as seen in figure 8 , which presents the comparable R-square values for all of our models, the predicted values for lobby participation rates and lobby registrations are very, very high, which reflects the strong relationship of both to the size of the potential lobby community, their shared independent variable. But this does not mean that the actual values of the two dependent variables are closely related. As seen in figure 7 , actual rates of lobby participation by health finance organizations are only weakly related to actual numbers of lobby registrations by such organizations across the states $(\mathrm{R}$-square $=0.04)$. In empirical terms, then, the strong relationship in figure 6 is

${ }^{17}$ Indeed, the only reason that the R-square value is not 1.0 is that the two polynomial specifications tend to treat extreme values in the curvilinear relationships a bit differently. When a simple linear specification has been used, the R-square values are uniformly 1.0. 


\section{Lowery, Gray, Monogan}

almost entirely spurious, a result of the two dependent variables' common relationship to their shared independent variable PLF. While both dependent variables are strongly related to that independent variable, they are related to it in very different ways. Nor, as seen in figure 9, is this unique to this sub-guild; the relationships between the actual values of the two dependent variables is very, very weak across all of the models.

This means that we cannot readily substitute information from one model into the other. If the Olson model fully captured the causal process running from size of the potential lobby population to participation rate, then we should be able to substitute participation rate into the ESA model in lieu of the two area terms of the model and generate a significant positive estimate for our substitute measure. Simply put, participation rate would have already built into it all of the information carried by the polynomial area estimates in the ESA model. But as seen in table 3, such substitution does not work, or at least does not work well. While the party dominance and agenda size variables retain the magnitudes observed in table 2 , three of eight participation rate estimates are wrongly signed and only three are significant. While we will see later that these three estimates can still tell us something useful, the overall pattern of results in table 3 suggests that we cannot readily translate empirical results from one model into the other.

Third, the two model have profoundly different implications for how we understand the nature of interest system bias, the linkage of individual member preferences and lobby objectives, the ultimate size of interest systems, and their consequences in terms of public policy (Lowery and Gray 2004b). The larger theoretical construct in which Olson's model is now employed (Schattschneider 1960; Olson 1965; 
1982; Schlozman 1994; Schlozman and Tierney 1986; McChesney 1997) suggests that interest systems will be profoundly biased toward small groups with large stakes in government, that the policies organizations lobby for have little connection with member's or sponsor's preferences, that policies are bought and sold like other commodities, and that interest systems can grow in an unconstrained manner even until economies collapse. In contrast, the neopluralist construct in which the ESA model is embedded suggests that bias is a complex artifact of the economies of scale of interest representation (Lowery and Gray 2004a; Lowery, Gray, and Fellowes 2004), that preferences of members matter (Salisbury 1969), that lobbying is often ineffective in securing policy returns (Heinz, Laumann, Nelson, and Salisbury 1993; Lowery, 2006), and interest systems are ultimately self-limiting in terms of size (Lowery and Gray 1995). Thus, while the models examined here are similar in many respects, they are parts of much larger constructs that are as profoundly antagonistic as any two theories in the discipline. Finding support for either Olson's or the ESA model of the construction of interest systems will certainly not topple one or another of these larger edifices. But determining which specification of the construction rules governing the interest communities best accounts for the density of interest systems will add empirical support to one or the other.

In short, we cannot and should not be agnostic about the two models. So, how should they be distinguished if our aggregate level analyses generate plausible support for both? Two methods seem appropriate. The first is to examine additional attributes of our aggregate models beyond the usual examination of the slope estimates of the area terms of the models. Three such attributes suggest that the ESA model should be accorded 


\section{Lowery, Gray, Monogan}

precedence. First, while R-square values are too often over-interpreted, it is also true that they provide us at least some information about our models that might be useful. In this case, as seen in figure 10, the R-square values generated for the Olson models in table 1 are uniformly smaller - and by large margins in several cases - than those generated for the ESA results in table 2. It would seem likely that if the results of one model were an artifact of processes tapped by the other that the latter would have more noise and hence a smaller coefficient of determination, especially so given the weak relationship between the actual values of the two dependent variables reported in figure 9. While hardly definitive, this strikes us as a small advantage for the ESA model.

Second, and perhaps a bit more telling, the estimates for the energy terms of the ESA model generated rather strong results. The energy variables were not part of Olson's original theoretical model. If lobbying communities are driven by free riding alone or by free riding mitigated by selective incentives, then the size of legislative agendas and the level of party competition should not matter. At a minimum, the strong results for these variables in the ESA model and even in some of the Olson models represent a mark against Olson.

And third, the very consistency of the results within the Olson models may constitute a strike against his specification. The ESA model suggests that density dependence characterizes to one degree or another most interest guilds. But because both the environmental resources that different guilds rely on and their capacities to sustain mobilization vary, this dependence will be expressed differently across guilds. Different guilds will have different economies of scale in interest representation. The ESA model does not, therefore, require that the slopes of the area terms of the several models be 


\section{Lowery, Gray, Monogan}

equally steep or density dependent (Lowery and Gray 2004a; Lowery, Gray, and Fellowes 2004). And the figures for the several sub-guilds comparable to figure 5 for health finance registrants are indeed quite different from each other.

In contrast, the full set of figures for the Olson model comparable to figure 4 for the health finance registrants are very similar. But this consistency seems inconsistent with Olson's model if all that really matters is the likelihood of having one's free riding exposed. This is especially evident in the two largest sub-guilds: direct patient care and health professionals. Yet, when the simple Olsonian model (comparable to figure 4) is applied to these models, as seen in figures 11 and 12, they produce results that are downwardly sloped in the same manner as the models of the other health sub-guilds. This strikes us as implausible that the level of free riding would not seem appreciably smaller when numbers of direct care offices increases from 500 to 20,000 or numbers of health professionals in states increase from 50,000 to $200,000{ }^{18}$ It would seem more plausible to expect - from Olson's view - that the large guilds would have extreme negative slopes that would then tail-off quickly with a residual of organizations lobbying for selective goods remaining within even relatively mid-sized populations of organizations with the potential to lobby. Yet, there is marked change in the predicted values of participation rate even across the mid-range population values in figures 11 and 12. To explain this within an Olson framework, we would need to account for why levels of free riding vary across very different guilds ranging in size across at least five orders

${ }^{18}$ Obviously, this would have been even a more severe problem had we included PLF (or area) in the Olson model only in a linear manner as is typical of most prior aggregatelevel tests. 
of magnitude in such a way as to produce very similar slopes for aggregate level participation rates. This would seem a difficult task.

Instead, it is perhaps best to apply Olson's model when numbers of potential lobbying organizations are relatively small, perhaps under a hundred or so. It is in such settings that perceptions about the probabilities of being observed free riding are likely to be more meaningful. If so, then some of the previously unexplained results in table 3 might be understandable. That is, we saw that substitution of participation rate for the polynomial specification of the area term of the ESA model generated only weak results for five of the eight models. Interestingly, however, the three models in which participation rate generated a correctly signed and discernible estimate were those for our three smallest guilds as measured by the number of organizations that might lobby health finance (state average $=63.47)$, local government $(71.40)$ and health education (13.64). Thus, it may well be true that Olson's model provides a good account of interest system density when the populations supporting interest guilds are very small. But after a threshold over which perceptions of the probability of being caught free riding are no longer plausibly altered by further increases in the numbers of organizations that might lobby, any first face evidence of the aggregate level consequences of free riding are more likely to be an artifact of density dependence of the type central to the ESA model of interest system density.

A second manner by which to distinguish the two models goes beyond the kind of cross-sectional aggregate level results examined here. First, time series of interest community density capture dynamic elements of vital rates of interest systems. Our interpretative problem stems ultimately from reliance on cross-sectional results that do 
Lowery, Gray, Monogan

not these for either model. There are, of course, compelling practical reasons why most studies of interest group populations rely on comparison of populations across industries or across jurisdictions. It is difficult to construct historic population data on interest systems. Given these difficulties, available time series data on populations of organized interests focus on only one jurisdiction using total numbers of organized interests (Brasher, Lowery, and Gray 1999; Wolak, Lowery, and Gray 2001; Lowery and Brasher 2004, 75) and/or a single policy domain Nownes 2004; Nownes and Lipinski 2005). This severely restricts the variance on key determinants of the ESA model, especially for its energy variables. Still, the evidence from the few time series analyses now available are clearly far more consistent with the expectations of the ESA model than they are with Olson's. Olson would lead us to expect that interest communities grow in a simple linear fashion as organizations slowly solve collective action problems using selective incentives. Instead, time series analyses - with Nownes (2004) and Nownes and Lipinski's (2005) analysis of gay and lesbian organizations perhaps serving as the gold standard of this type of work - shows clear evidence of slow growth with few births and many deaths in the legitimation phase of an interest guild, rapid growth with many births and few deaths following initial legitimation, and little growth with many deaths and few births during the mature density dependent stage of population development. This sshaped pattern is a hallmark of environmentally constrained population growth (Hannan and Freeman 1989). These results do not tell us everything that we wish to know about interest communities, such as their responsiveness to short term changes in policy and politics. Still, their consistency with ESA expectations suggests that it offers a superior interpretation. 
Lowery, Gray, Monogan

A second and perhaps even more important literature that can aid our interpretation is comprised of micro-level analyses of the collective action problem and the role of organizational dependence on environmental resources. There has now been an accumulation of results which cut against Olson's analysis in a number of ways. The collective action problem does not appear to be as severe at the individual-level as Olson proposed (Hansen 1985; Moe 1980; Marwell and Ames 1979). Entrepreneurial leaders (Salisbury 1969; Rosenstone and Hansen 1993; Verba, Schlozman, and Brady 1995) have a clear incentive to identify and cultivate members and sponsors (Gray and Lowery 1996b) through a variety of means going well beyond selective incentives (Clark and Wilson 1961; Leighley 1996) and patron support (Berry 1999). Thus, many organizations that Olson would have expected to have great difficulty forming, have prospered (Bosso 2005). Yet, many organizations that do mobilize then fail, which Olson did not expect. Equally important, organizational-level analyses have found that that variations in the vital rates of interests across populations are recognized by group leaders (Gray and Lowery 1997b), results that support the micro-level foundations of the ESA model. Together, this suggests, as noted by Baumgartner and Leech $(1998,75)$, "the question of whether the problems discussed by Olson may have been given more prominence in the interest-group literature than they deserve."

\section{Conclusion}

We have seen that the Olson's $(1965 ; 1982)$ collective action model and Gray and Lowery's (1996a) ESA model - are closely related to each other in terms of how they are tested at the aggregate-level with cross-sectional data. This means, unfortunately, that results supportive of one model can equally support the other. We have explained why 


\section{Lowery, Gray, Monogan}

this is so and illustrated this close relationship with data on several sub-guilds of health interest organizations in the American states,. On their own terms, these results cannot fully resolve our problem of identifying which model more validly accounts for the structure of interest communities. However, we have also identified several secondary features of these cross-sectional findings that support, we believe, the ESA model rather than Olson's. And we have buttressed this evidence by reference to time series studies and more micro-level analyses that provide contextual support for our interpretation. In our view, the weight of evidence, even if indirect, clearly favors the ESA model. Still, we do not want to suggest that Olson's notion of collective action is irrelevant. Rather, we think that it may still provide a telling account, perhaps in conjunction with elements of the ESA model, of how small sub-guilds of organizations form. It is only within such small sub-guilds that the likelihood of exposure of free riding is plausibly meaningful within the range of observed numbers of members or organizations from which lobby organizations are drawn. For larger sub-guilds, defined in terms of shared reliance on environmental resources and/or public policies with collective good features, propensities to free ride are already likely to be constants. In such settings, the variables cited by the ESA model are far more likely to ultimately determine the density and the diversity of the interest community. The raw materials produced via bottom-up processes are ultimately sculpted into populations by top-town pressures.

This assessment of our findings has two implications. First and more narrowly, prior aggregate-level, cross-sectional tests of Olson's hypothesis should be re-examined in terms of what they say about the ESA model. Conversely, prior work on the ESA model should be re-examined in terms of Olson's conjectures. Second, comparison of 
the two models raises some interesting questions about the role of contextual theories within our discipline. The prominence assigned to Olson's model results not only from its earlier introduction, but also from its appeal to powerful analytic traditions within the discipline. Whether they are based on psychology or economics, we tend to like explanations that are rooted in individual-level models of behavior. Explanations tapping older sociological references to group properties are viewed suspiciously. But this often appropriate bias can lead to error when we too freely extrapolate from individual behavior to the population level without asking what might happen once individuals interact. This, of course, is precisely what Olson did when making the leap from The

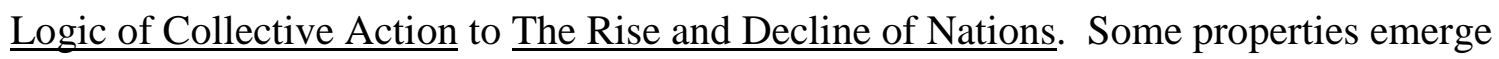
only at the population-level. Interest system density and diversity are such properties. Yet, we have seen that they powerfully condition how many and what kinds of organized interests can survive within interest systems. 
Lowery, Gray, Monogan

\section{References}

Aldrich, Howard E. and Jeffrey Pfeffer. 1976. "Environments of Organizations.” Annual Review of Sociology 2: 79-105.

Andres, Gary J. 1985. "Business Involvement in Campaign Finance: Factors Influencing the Decision to Form a Coporate PAC." PS 18: 156-181.

Baumgartner, Frank R. and Beth L. Leech. 1998. Basic Interests. Princeton: Princeton University Press.

Berry, Jeffrey M. 1999. The New Liberalism. Washington, D.C.: Brookings Institution Press.

Bois, John L. 1989. “Money, Business, and the State: Material Interests, Fortune 500 Corporations, and the Size of Political Action Committees." American Sociological Review 54: 821-833.

Bosso, Christopher, J. 2005. Environment, Inc. Lawrence: Kansas: University of Kansas Press.

Bowling, Cynthia J. and Margaret R. Ferguson. 2001. "Divided Government, Interest Representation, and Policy Differences: Competing Explanations of Gridlock in the Fifty States." Journal of Politics 63: 182-206.

Brasher, Holly, David Lowery, and Virginia Gray. 1999. "State Lobby Registration Data: The Anomalous Case of Florida (and Minnesota too!).” Legislative Studies Quarterly 24 (2): 303-314.

Chong, Dennis. 1991. Collective Action and the Civil Rights Movement. Chicago: University of Chicago Press.

Clark, Peter B. and James Q. Wilson. 1961. "Incentives Systems: A Theory of 
Lowery, Gray, Monogan

Organizations.” Administrative Science Quarterly 6: 129-166.

Gray, Virginia and David Lowery. 2001. "The Expression of Density Dependence in State Communities of Organized Interests." American Politics Quarterly 29 (4): 374-391.

Gray, Virginia and David Lowery. 1998. "State Lobbying Regulations and Their Enforcement: Implications for the Diversity of State Interest Communities.” State and Local Government Review 30: 78-91.

Gray, Virginia and David Lowery. 1997a. "Reconceptualizing PAC Formation: It's Not a Collective Action Problem, and It May Be an Arms Race." American Politics Quarterly 25 (3): 319-346.

Gray, Virginia and David Lowery. 1997b. "Life in a Niche: Mortality Anxiety Among Organized Interests in the American States." Political Research Quarterly 50 (1): 25-47.

Gray, Virginia and David Lowery. 1996a. The Population Ecology of Interest Representation. Ann Arbor, Michigan: University of Michigan Press.

Gray, Virginia and David Lowery. 1996b. “A Niche Theory of Interest Representation.” Journal of Politics 59 (1): 91-111.

Gray Virginia, David Lowery, Matthew Fellowes, and Jennifer Anderson, 2005. "Understanding the Demand-Side of Lobbying: Interest System Energy in the American States.” American Politics Research 33 (1): 404-434.

Grier, Kevin B., Michael C. Munger, and Brian E. Roberts. 1994. "The Determinants of Industry Political Activity, 1978-1986." American Political Science Review 88: 911-926. 
Lowery, Gray, Monogan

Grier, Kevin B., Michael C. Munger, and Brian E. Roberts. 1991. “The Industrial Organization of Corporate Political Participation." Southern Economic Journal 57: 727-738.

Hannan, Michael T. and John Freeman. 1989. Oranizational Ecology. Cambridge, Massachusetts: Harvard University Press.

Hansen, John Mark. 1985. “The Political Economy of Group Membership.” American Political Science Review 79: 79-96.

Hansen, Wendy L. and Neil J. Mitchell. 2000. "Disaggregating and Explaining Corporate Political Activity: Domestic and Foreign Corporation in National Politics.” American Political Science Review 94: 891-903.

Heinz, John P., Edward O. Laumann, Robert L. Nelson, and Robert Salisbury. 1990. “Inner Circles or Hollow Cores? Elite Networks in National Policy Systems." Journal of Politics 52 (2): 356-390.

Humphries, Craig. 1991. "Corporations, PACs and the Strategic Link Between Contributions and Lobbying Activities." Western Political Quarterly 44: 353-372.

Leighley, Jan. 1996. "Group Membership and the Mobilization of Political Participation.” Journal of Politics 58: 447-463.

Lowery, David and Holly Brasher. 2004. Organized Interests and American Government. Boston: McGraw Hill.

Lowery, David. 2007. “Why Do Organized Interest Lobby? A Multi-Goal, Multi-Context Theory of Lobbying." Polity 39 (1), 29-54.

Lowery, David and Virginia Gray. 2004a. "Bias in the Heavenly Chorus: Interests in Society and Before Government." Journal of Theoretical Politics 16 (1): 5-30. 
Lowery, Gray, Monogan

Lowery, David and Virginia Gray. 2004b. “A Neopluralist Perspective on Research on Organized Interests.” Political Research Quarterly 57 (1): 163-175.

Lowery, David Virginia Gray, Jennifer Anderson, and Adam J. Newmark. 2004.

“Collective Action and the Mobilization of Institutions." Journal of Politics 66 (2): $684-705$.

Lowery, David, Virginia Gray, and Matthew Fellowes 2005. "Sisyphus Meets the Borg: Understanding the Diversity of Interest Communities." Journal of Theoretical Politics 17 (1): 41-74.

Lowery, David Virginia Gray, Matthew Fellowes, and Jennifer Anderson. 2004. "Living in the Moment: Lags, Leads, and the Link Between Legislative Agendas and Interest Advocacy." Social Science Quarterly 85 (2): 463-477.

Lowery, David and Virginia Gray. 1997. “How Some Rules Just Don’t Matter: The Regulation of Lobbyists.” Public Choice 91: 139-147.

Lowery, David and Virginia Gray. 1995. "The Population Ecology of Gucci Gulch, or the Natural Regulation of Interest Group Numbers in the American States." American Journal of Political Science 39 (1): 1-29.

Lowery, David and Virginia Gray. 1994. "Do Lobbying Regulations Influence Lobbying Registrations.” Social Science Quarterly 75 (2): 382-384.

Marwell, Gerald and Ruth E. Ames. 1979. "Experiments on the Provision of Public Goods. I. Resources, Interest, Group Size, and the Free Rider Problem.” American Journal of Sociology 85: 1335-1360.

Masters, Marick F. and Gerald D. Keim. 1985. "Determinants of PAC Participation Among Large Corporations.” Journal of Politics 47: 1158-1173. 
Lowery, Gray, Monogan

McChesney, Fred S. 1997. Money for Nothing: Politicians, Rent Extraction, and Political Extortion. Cambridge: Harvard University Press.

McKeown, Timothy. 1994. "The Epidemiology of Corporate PAC Formation, 1975-84." Journal of Economic Behavior and Organization 24: 153-168.

Mitchell, Neil F., Wendy L. Hansen, and Eric Jepsen. 1997. “The Determinants of Domestic and Foreign Corporate Political Activity.” Journal of Politics 59: 10961072.

Moe, Terry M. 1980. The Organization of Interests. Chicago: University of Chicago Press.

Nownes, Anthony. 2004. “The Population Ecology of Interest Group Formation: Mobilizing for Gay and Lesbian Rights in the United States, 1950-1998." British Journal of Political Science 28: 49-76.

Nownes, Anthony and Daniel Lipinski. 2005. “The Population Ecology of Interest Death Formation: Mobilizing for Gay and Lesbian Rights in the United States, 19451998.” British Journal of Political Science 29: 303-319.

Olson, Mancur, Jr. 1965. The Logic of Collective Action. Cambridge, Massachusetts: Harvard University Press.

Olson, Mancur, Jr. 1982. The Rise and Decline of Nations. New Haven: Yale University Press.

Powell, Walter W. and Paul J. Dimagio. 1991. The New Institutionalism in Organizational Analysis. Chicago: University of Chicago Press.

Rosenstone, Steven J. and John Mark Hansen. 1993. Mobilization, Participation, and Democracy in America. New York: Macmillan. 
Lowery, Gray, Monogan

Rothenberg, Lawrence. 1992. Linking Citizens to Government. New York: Cambridge University Press.

Salisbury, Robert. 1969. “An Exchange Theory of Interest Groups.” Midwest Journal of Political Science 13 (1): 1-32.

Schattschneider, E. E. 1960. The Semisovereign People. New York: Holt, Rinehart, and Winston.

Schlozman, Key Lehman. 1984. "What Accent the Heavenly Chorus? Political Equality and the American Pressure System.” Journal of Politics 46: 1006-1032.

Schlozman, Kay Lehman and John T. Tierney. 1986. Organized Interests and American Democracy. New York: Harper and Row.

Truman, David. 1951. The Governmental Process. New York: Alfred A. Knopf.

Verba, Sidney, Kay Lehman Schlozman, and Henry E. Brady. 1995. Voice and Equality. Cambridge: Harvard University Press.

Wilkerson, John D., T. Jens Feeley, Nicole S. Schiereck, and Christina Sue. 1993. "Using Bills and Hearings to Trace Attention in Congress: Policy Windows in Health Care Legislating.” In Policy Dynamics. Eds. Frank R. Baumgartner and Bryan D. Jones. Chicago: University of Chicago Press, 250-269.

Wolak, Jennifer, David Lowery, and Virginia Gray. 2001. "California Dreaming: Outliers, Leverage, and Influence in Comparative State Political Analysis." State Politics and Policy Quarterly 1 (3): 255-272. 


\section{Lowery, Gray, Monogan}

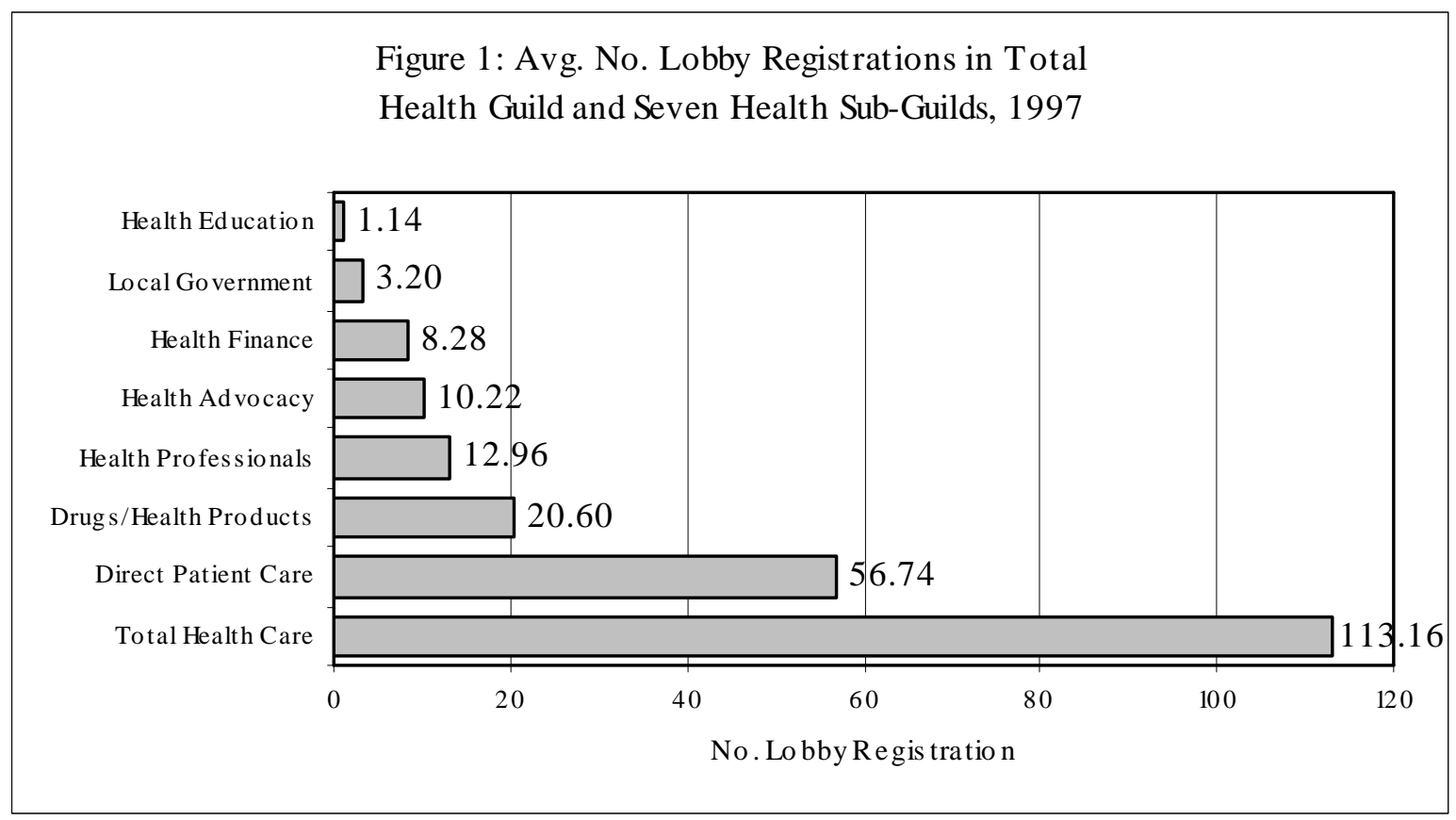




\section{Lowery, Gray, Monogan}

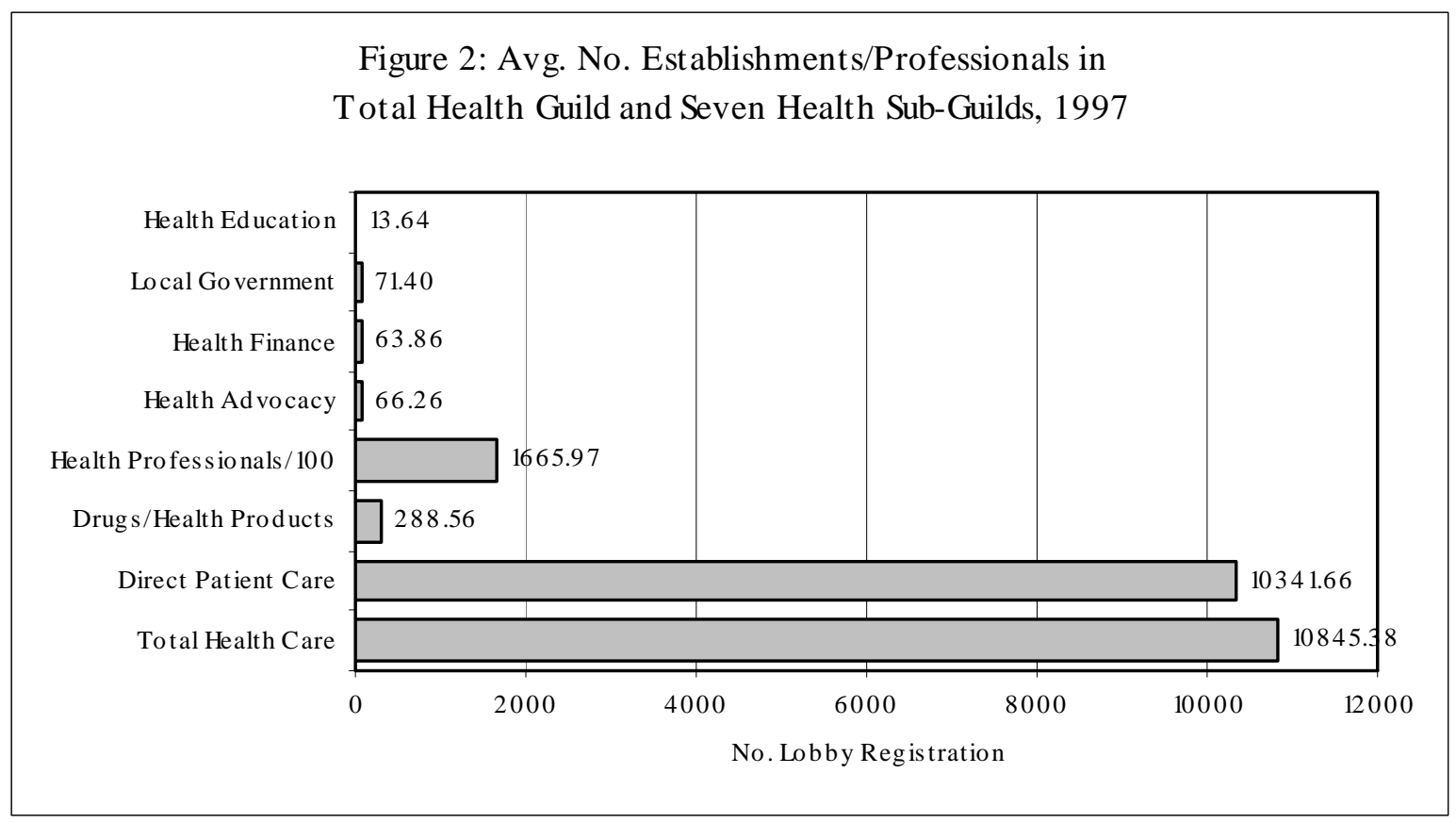




\section{Lowery, Gray, Monogan}

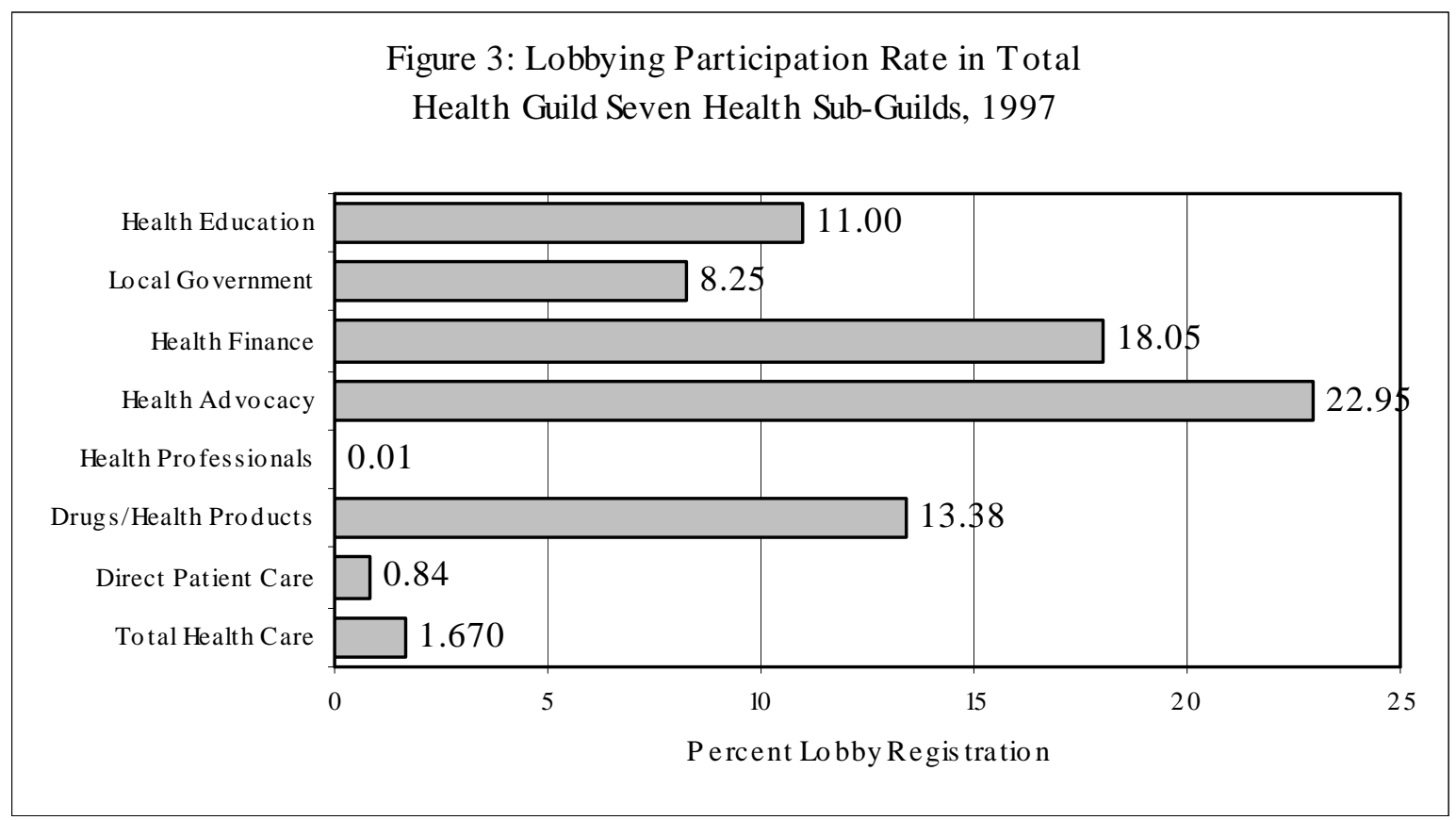




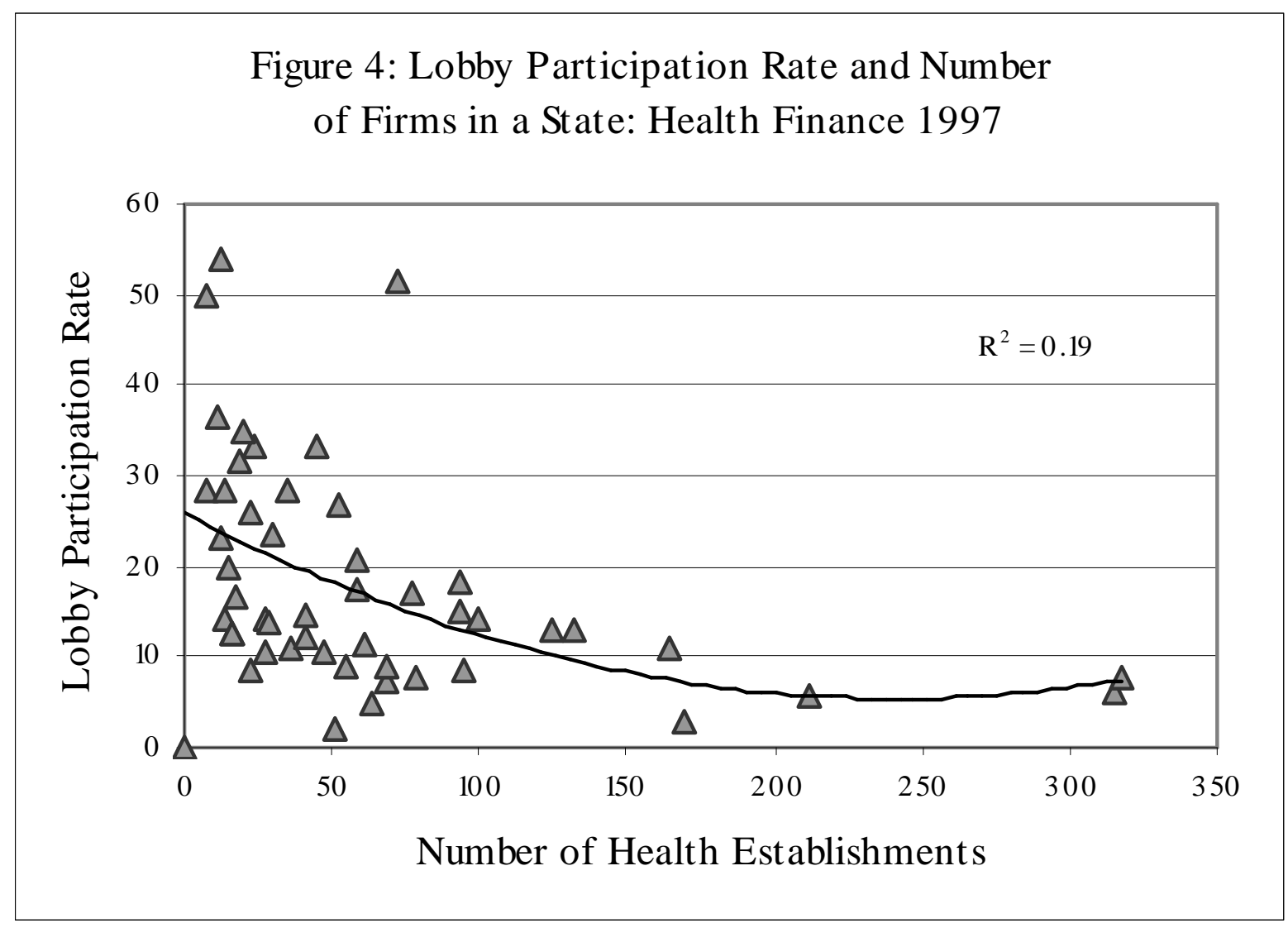




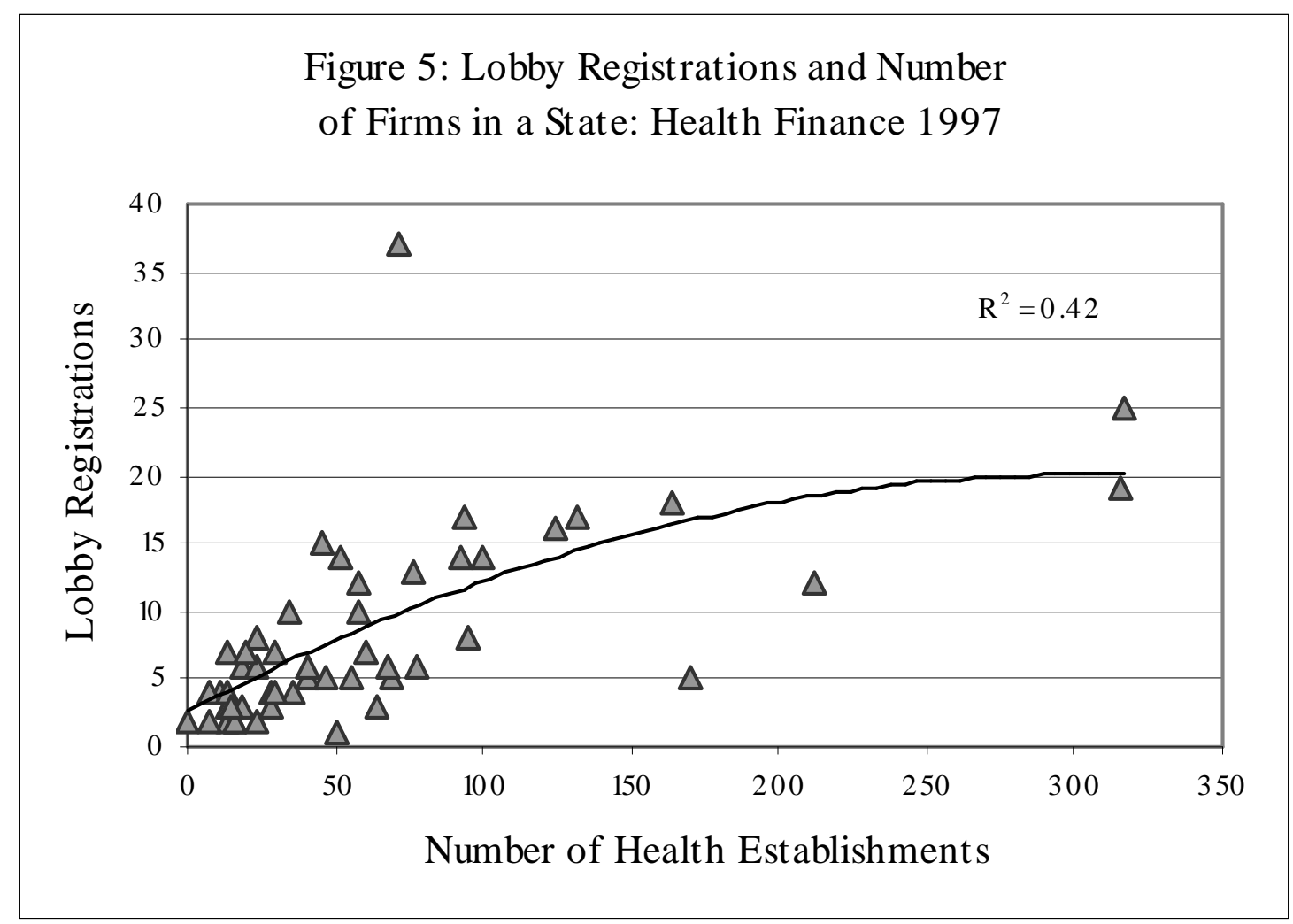




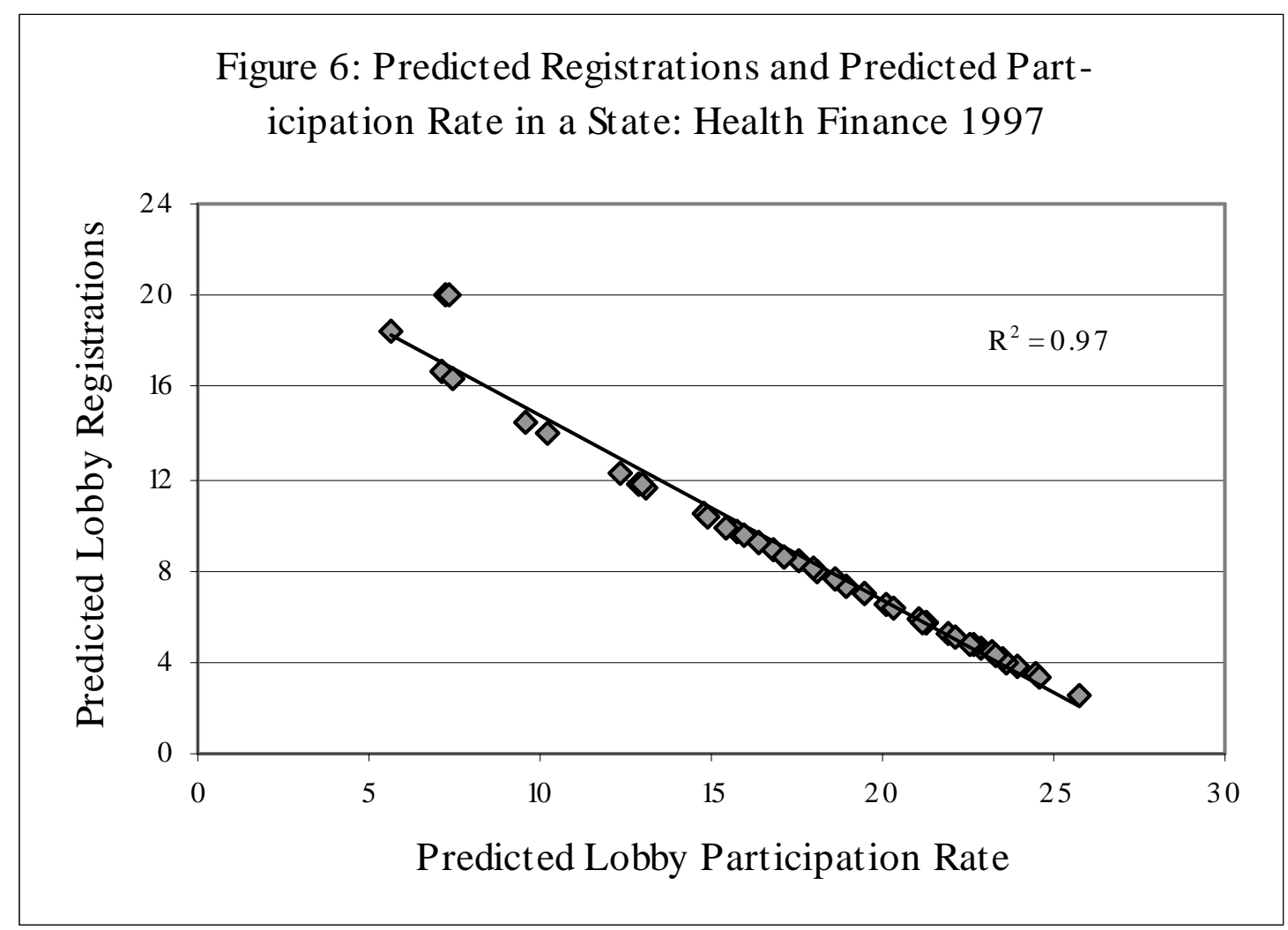




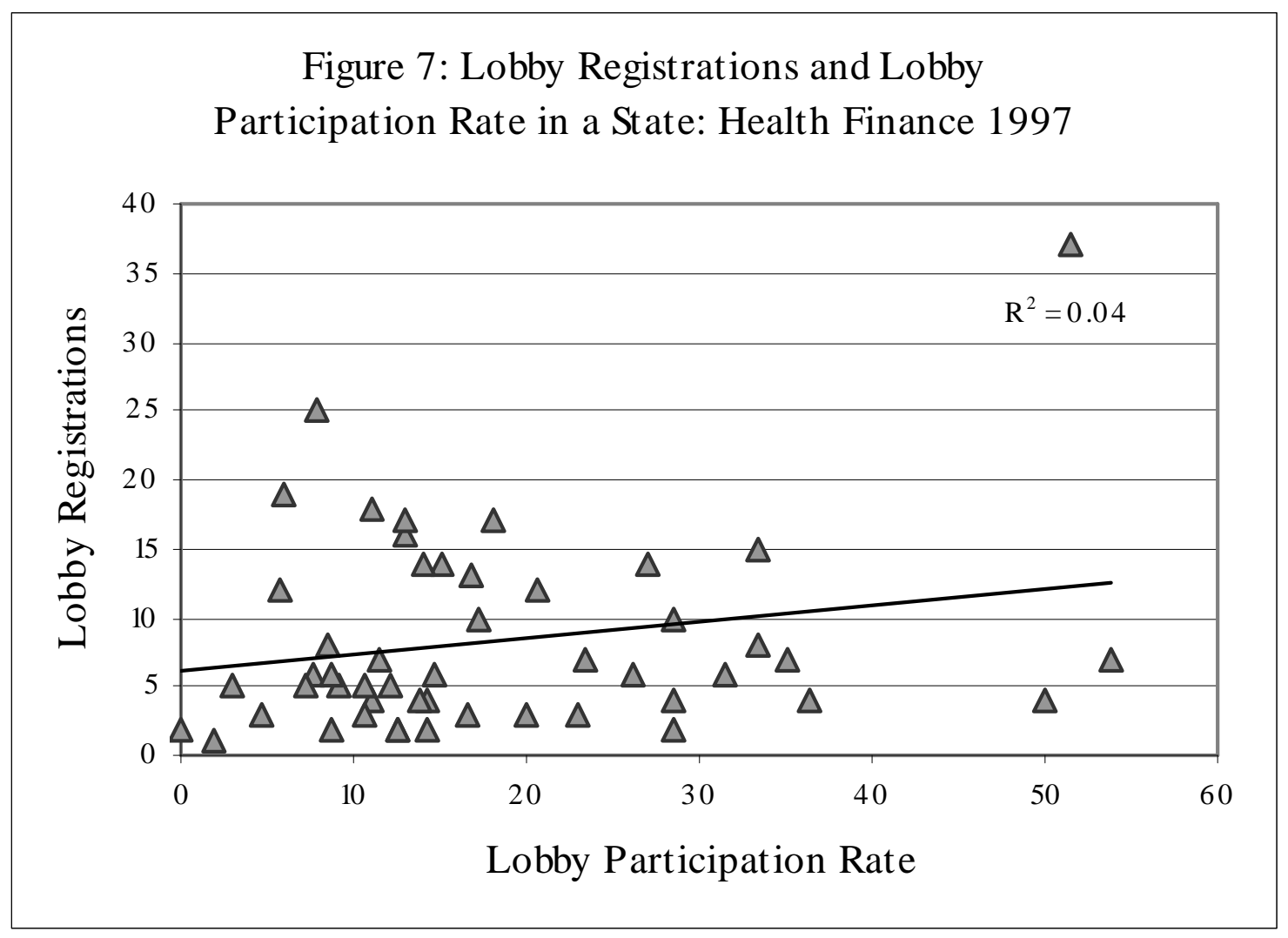




\section{Lowery, Gray, Monogan}

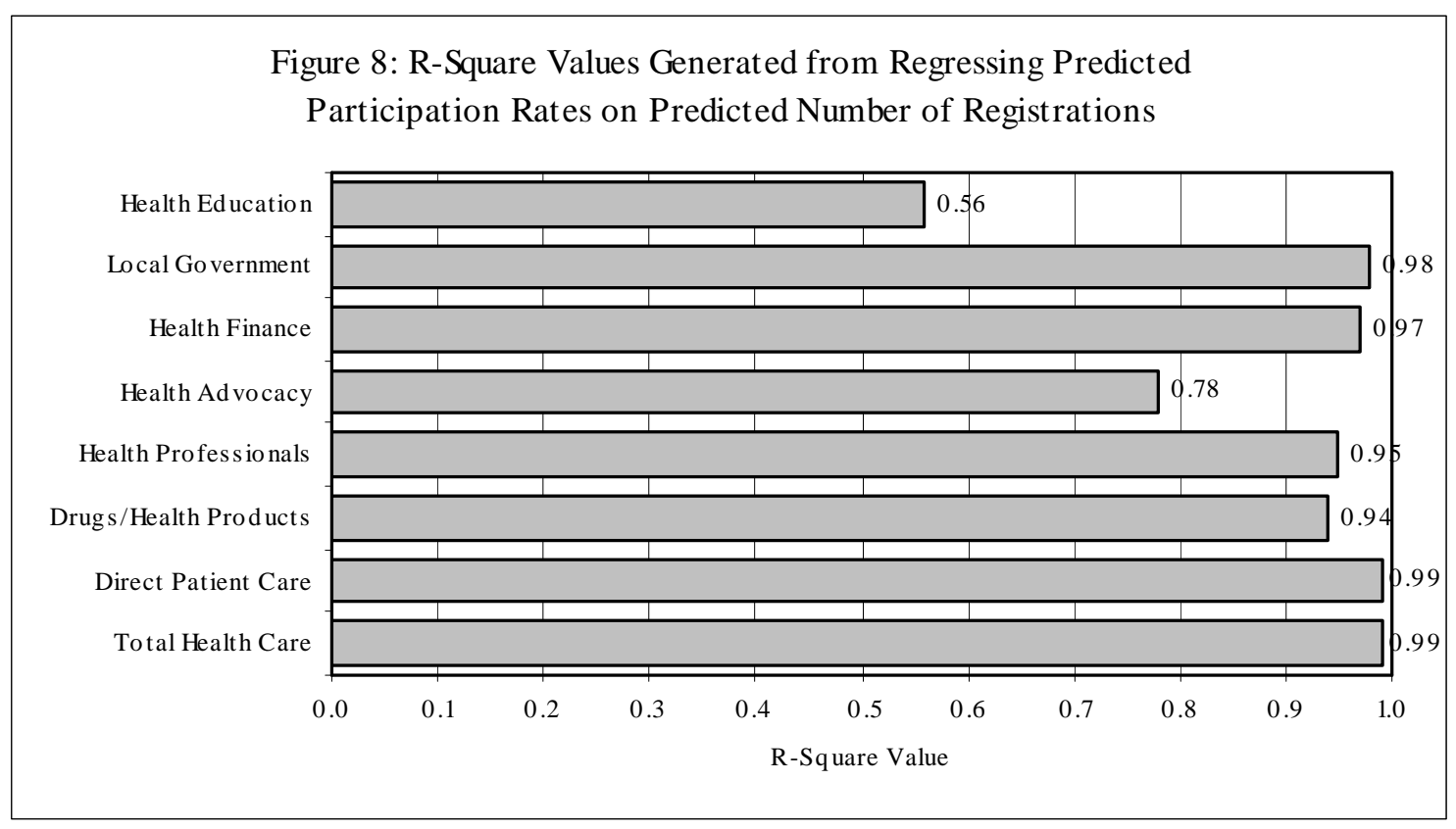




\section{Lowery, Gray, Monogan}

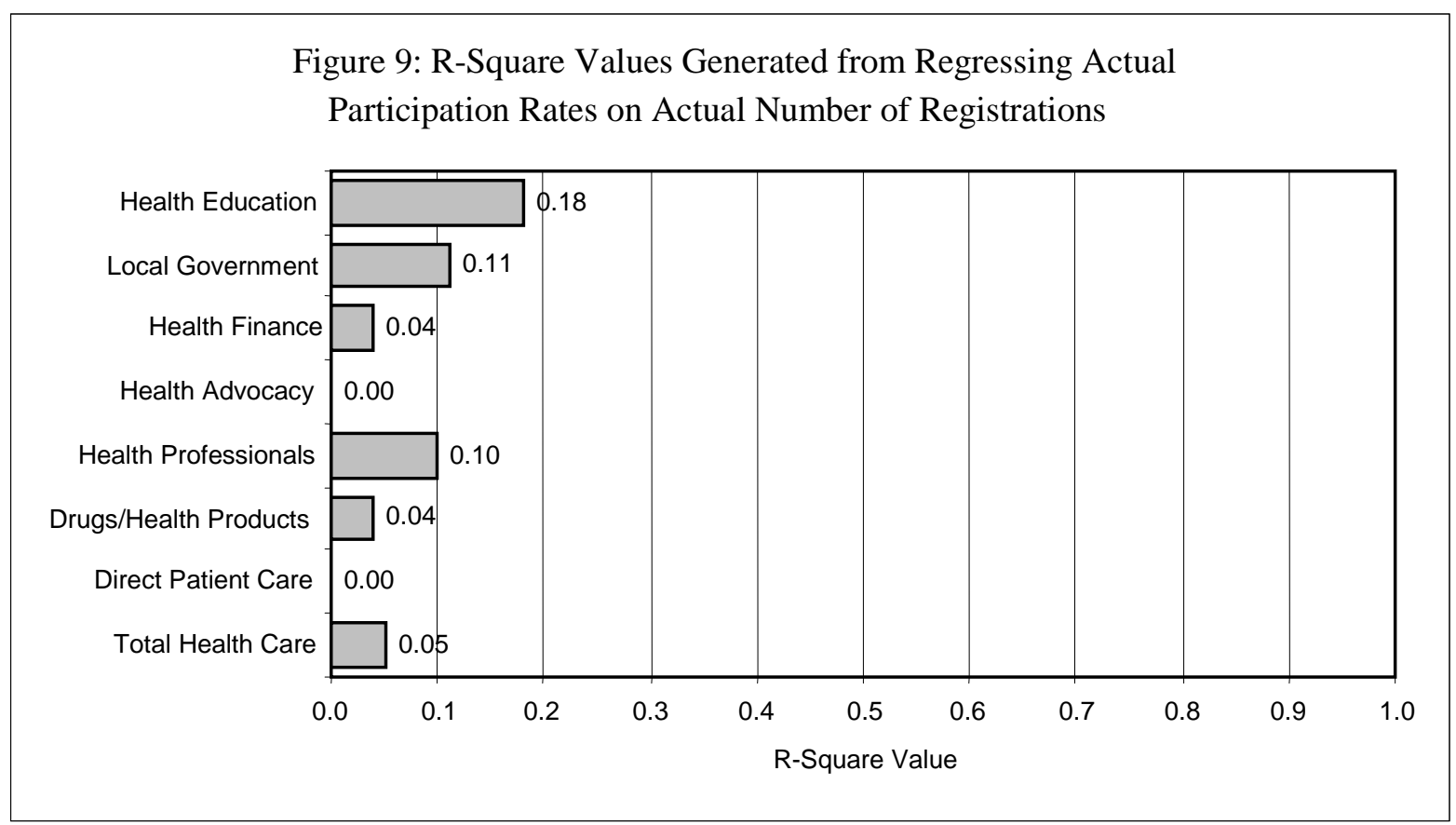




\section{Lowery, Gray, Monogan}

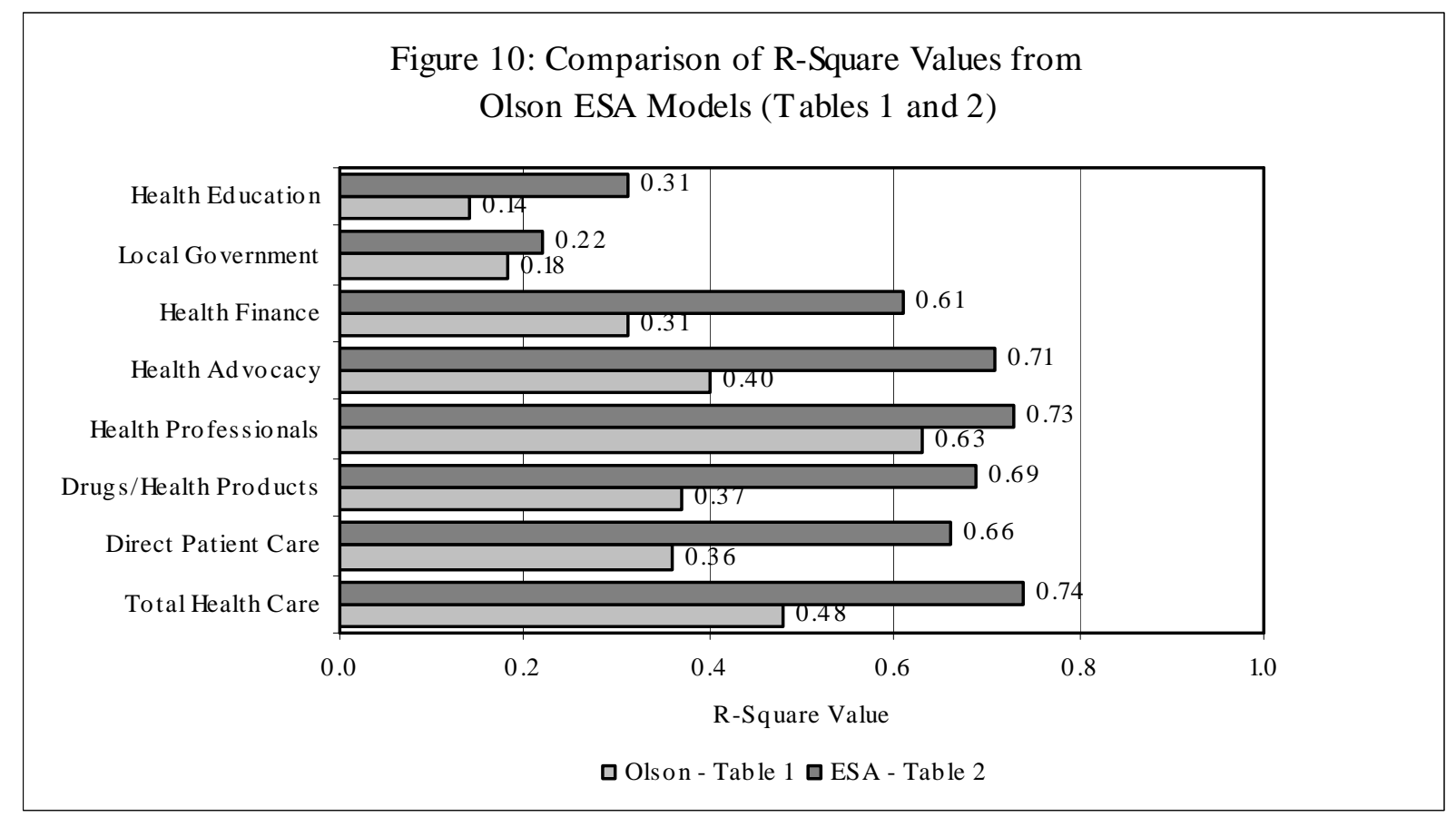




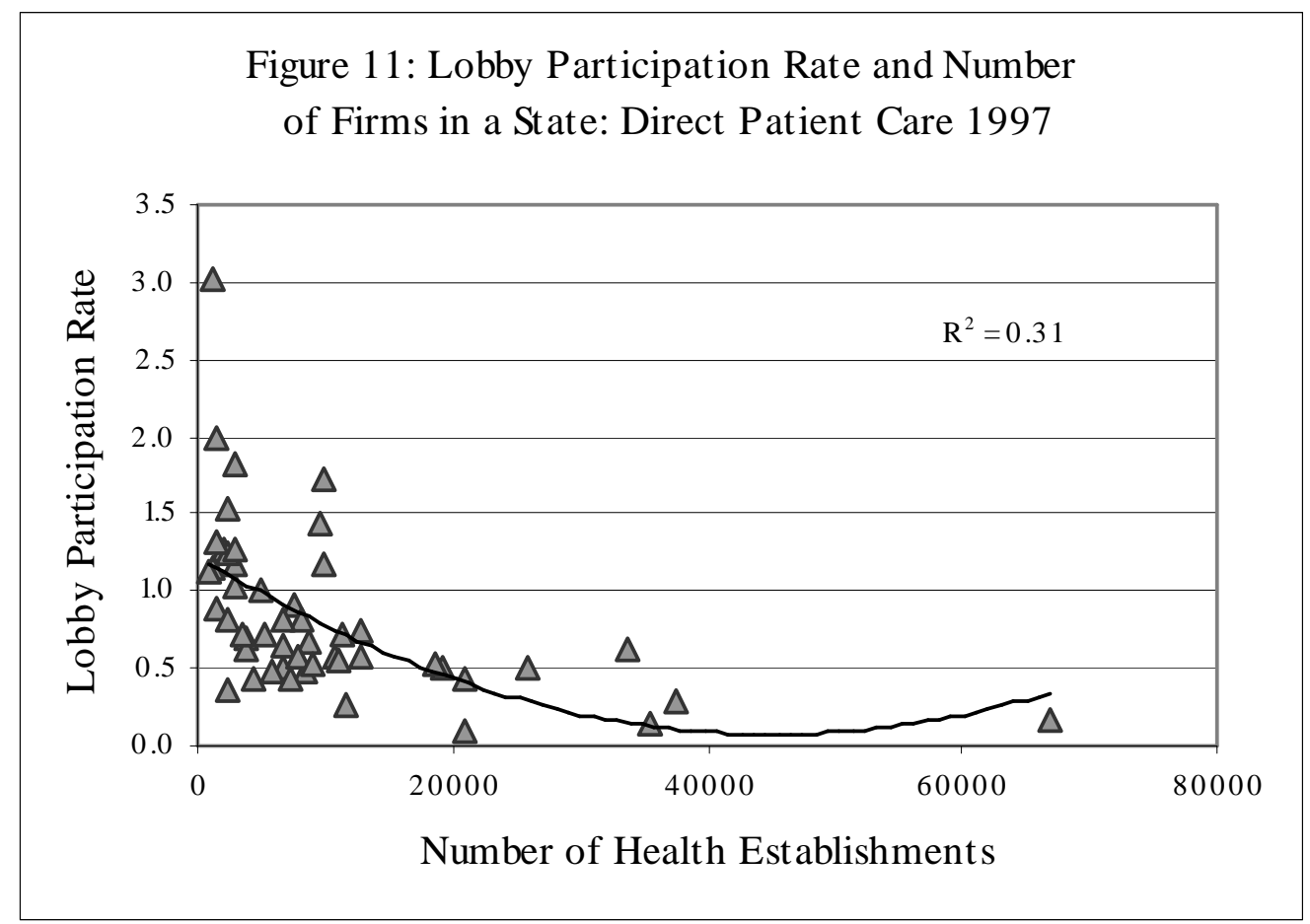




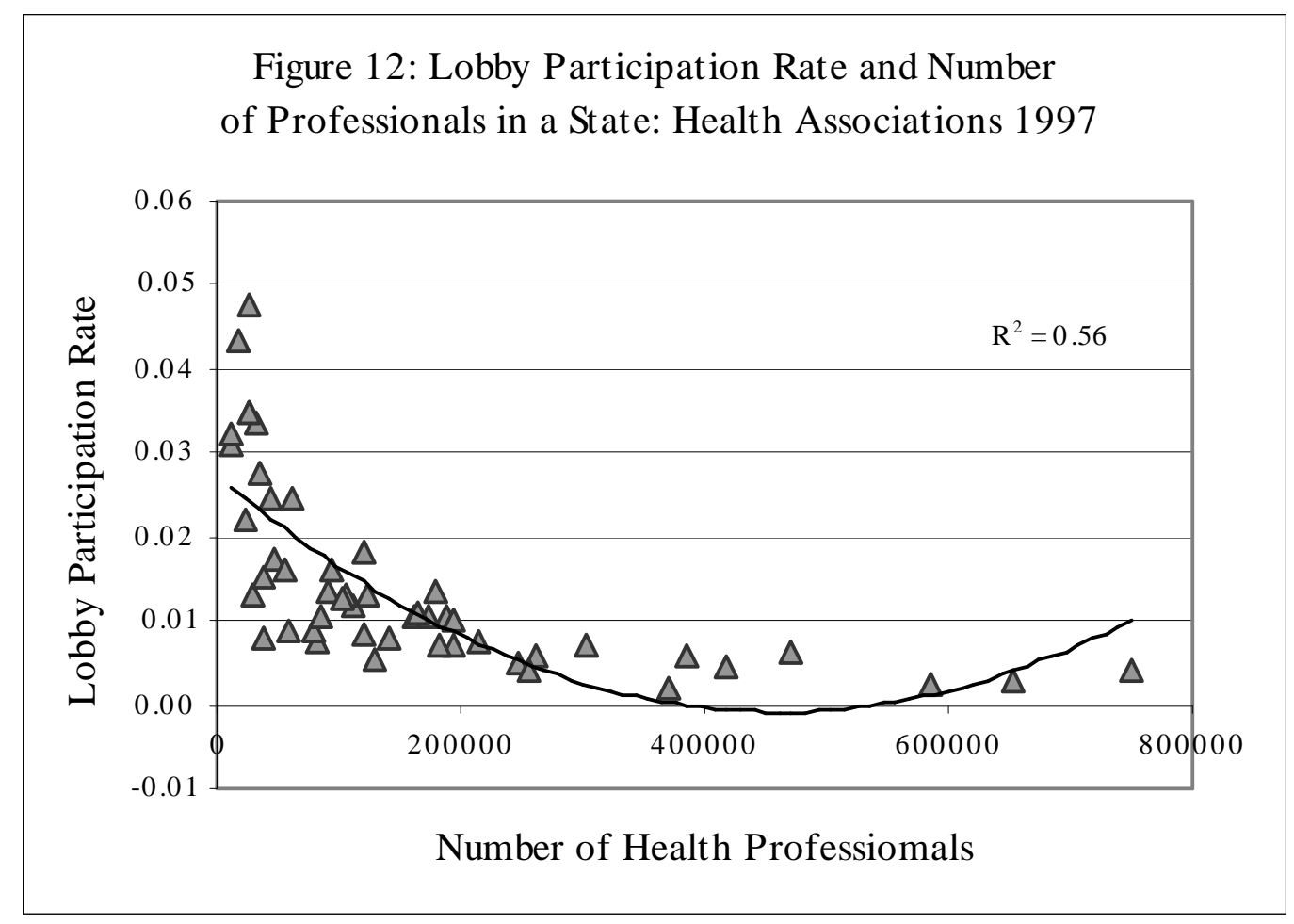




\section{Lowery, Gray, Monogan}

Table 1: Collective Action Models of Lobby Participation

Rates: Total Health Guild and Seven Sub-Guilds, 1997 ( $n=48)$

\begin{tabular}{|c|c|c|c|c|c|c|}
\hline \multirow{2}{*}{$\begin{array}{l}\text { Dependent } \\
\text { Variables: } \\
\% \text { Registered } \\
\text { or LR/PLR }\end{array}$} & \multicolumn{4}{|c|}{ Independent Variables } & \multirow[b]{2}{*}{ Constant } & \multirow[b]{2}{*}{ R-Square } \\
\hline & $\begin{array}{l}\text { Area or } \\
\text { PLR }\end{array}$ & $\begin{array}{c}\text { Area / PLR } \\
\text { Squared }\end{array}$ & $\begin{array}{c}\text { Party } \\
\text { Dominance }\end{array}$ & $\begin{array}{l}\text { Agenda } \\
\text { Size }\end{array}$ & & \\
\hline Total & $-1.59 * *$ & $0.99 * *$ & $-0.31 * *$ & 0.02 & 4.67 & 0.48 \\
\hline Health Care & -5.31 & 3.34 & -2.61 & 0.17 & & \\
\hline Direct & $-1.34 * *$ & $0.78 *$ & $-0.27 *$ & 0.07 & 2.17 & 0.36 \\
\hline Patient Care & -4.02 & 2.35 & -0.20 & 0.41 & & \\
\hline Drugs/Health & $-1.41 * *$ & $0.99 * *$ & -0.17 & 0.01 & 34.85 & 0.37 \\
\hline Products & -4.46 & 3.26 & -1.25 & -0.06 & & \\
\hline Health Prof. & $-2.13 * *$ & $1.56 * *$ & $-0.30 * *$ & -0.12 & 0.05 & 0.63 \\
\hline Associations & -7.10 & 5.24 & -2.88 & -1.03 & & \\
\hline Health & $-1.64 * *$ & $1.15 * *$ & $-0.38 * *$ & -0.03 & 82.70 & 0.40 \\
\hline Advocacy & -4.42 & 3.14 & -2.89 & -0.22 & & \\
\hline Health & $-1.00 * *$ & 0.48 & 0.04 & $0.37 * *$ & 18.98 & 0.31 \\
\hline Finance & -2.55 & 1.25 & 0.30 & 2.55 & & \\
\hline Local & $-0.71 *$ & 0.40 & $-0.29 *$ & -0.04 & 33.98 & 0.18 \\
\hline Gov't & -2.04 & 1.14 & -2.01 & -0.25 & & \\
\hline Health & $-0.91 *$ & 0.62 & $-0.29 *$ & 0.11 & 57.01 & 0.14 \\
\hline Education & -2.06 & 1.46 & -1.92 & 0.73 & & \\
\hline
\end{tabular}

$* *=p<0.01, *=p<0.05$, one-tailed tests. Coefficients are standardized. Values below the coefficients are t-values. Dependent variables are the percentage of establishments (or professionals for Health Professional Associations) that are registered to lobby. The measures of the independent variables are are discussed in the text. 


\section{Lowery, Gray, Monogan}

Table 2: Energy, Stability, Area Models of Interest Community

Density: Total Health Guild and Seven Sub-Guilds, 1997 (n=48)

\begin{tabular}{|c|c|c|c|c|c|c|}
\hline \multirow{2}{*}{$\begin{array}{l}\text { Dependent } \\
\text { Variables: } \\
\text { No. Registered } \\
\text { or LR }\end{array}$} & \multicolumn{4}{|c|}{ Independent Variables } & \multirow[b]{2}{*}{ Constant } & \multirow[b]{2}{*}{ R-Square } \\
\hline & $\begin{array}{c}\text { Area or } \\
\text { PLR }\end{array}$ & $\begin{array}{c}\text { Area / PLR } \\
\text { Squared }\end{array}$ & $\begin{array}{c}\text { Party } \\
\text { Dominance }\end{array}$ & $\begin{array}{l}\text { Agenda } \\
\text { Size }\end{array}$ & & \\
\hline Total & $1.15 * *$ & $-0.94 * *$ & $-0.36 * *$ & $0.43 * *$ & 213.06 & 0.74 \\
\hline Health Care & 5.27 & -4.45 & -4.24 & 4.24 & & \\
\hline Direct & $1.19 * *$ & $-1.04 * *$ & $-0.32 * *$ & $0.40 * *$ & 102.56 & 0.66 \\
\hline Patient Care & 4.87 & -4.29 & -3.24 & 3.44 & & \\
\hline Drugs/Health & $0.81 * *$ & $-0.69 * *$ & $-0.40 * *$ & $0.44 * *$ & 42.26 & 0.69 \\
\hline Products & 3.64 & -3.24 & -4.26 & 3.89 & & \\
\hline Health Prof. & $1.00 * *$ & $-0.73 * *$ & $-0.38 * *$ & $0.40 * *$ & 22.49 & 0.73 \\
\hline Associations & 3.92 & -2.89 & -4.35 & 4.23 & & \\
\hline Health & $0.61 *$ & -0.19 & $-0.39 * *$ & $0.25 *$ & 23.49 & 0.71 \\
\hline Advocacy & 2.38 & -0.76 & -4.26 & 2.37 & & \\
\hline Health & $0.93 * *$ & $-0.63 *$ & -0.20 & $0.45 * *$ & 9.98 & 0.61 \\
\hline Finance & 3.21 & -2.21 & -1.91 & 4.26 & & \\
\hline Local & 0.45 & -0.39 & $-0.35 * *$ & 0.11 & 9.43 & 0.22 \\
\hline Gov't & 1.34 & -1.14 & -2.50 & 0.74 & & \\
\hline Health & 0.06 & 0.21 & $-0.27 *$ & $0.24 *$ & 3.42 & 0.31 \\
\hline Education & 0.16 & 0.56 & -1.96 & 1.71 & & \\
\hline
\end{tabular}

$* *=p<0.01, *=p<0.05$, one-tailed tests. Coefficients are standardized. Values below the coefficients are t-values. Dependent variables are the number of lobby registrations by organizations in 1997.

The measures of the independent variables are discussed in the text. 


\section{Lowery, Gray, Monogan}

Table 3: Substituting Lobby Participation Rates for the Supply/Area Terms of the ESA Model: Total Health Guild and Seven Sub-Guilds, 1997 ( $n=48)$

\begin{tabular}{|c|c|c|c|c|c|c|}
\hline \multirow{2}{*}{$\begin{array}{l}\text { Dependent } \\
\text { Variables: } \\
\text { Number } \\
\text { Registered }\end{array}$} & \multirow{2}{*}{$\begin{array}{c}\text { Avg. } \\
\text { Number } \\
\text { of } \\
\text { Est. }\end{array}$} & \multicolumn{3}{|c|}{ Independent Variables } & \multirow[b]{2}{*}{ Constant } & \multirow[b]{2}{*}{ R-Square } \\
\hline & & $\begin{array}{l}\text { Participation } \\
\% \text { (LR/PLR) }\end{array}$ & $\begin{array}{c}\text { Party } \\
\text { Dominance }\end{array}$ & $\begin{array}{l}\text { Agenda } \\
\text { Size }\end{array}$ & & \\
\hline Total & & -0.10 & $-0.51 * *$ & $0.46 * *$ & 343.49 & 0.58 \\
\hline Health Care & 10845.38 & -1.00 & -5.14 & 4.47 & & \\
\hline Direct & & 0.05 & $0.46 * *$ & $0.44 * *$ & 166.60 & 0.47 \\
\hline Patient Care & 10341.66 & 0.40 & -4.10 & 0.39 & & \\
\hline Drugs/Health & & -0.03 & $-0.52 * *$ & $0.47 * *$ & 56.94 & 0.60 \\
\hline Products & 288.56 & -0.33 & -5.35 & 4.75 & & \\
\hline Health Prof. & & -0.15 & $-0.53 * *$ & $0.44 * *$ & 33.69 & 0.63 \\
\hline Associations & -- & -1.57 & -5.69 & 4.57 & & \\
\hline Health & & 0.08 & $-5.24 * *$ & $0.50 * *$ & 30.93 & 0.60 \\
\hline Advocacy & 66.26 & 0.78 & -5.39 & 4.97 & & \\
\hline Health & & $0.20 *$ & $-0.38 * *$ & $0.53 * *$ & 19.94 & 0.53 \\
\hline Finance & 63.86 & 1.89 & -3.50 & 4.91 & & \\
\hline Local & & $0.43 * *$ & $-0.30 * *$ & 0.17 & 8.24 & 0.37 \\
\hline Gov't & 71.40 & 3.55 & -2.42 & 1.43 & & \\
\hline Health & & $0.37 * *$ & $-0.27 *$ & $0.33 * *$ & 3.21 & 0.38 \\
\hline Education & 13.64 & 3.06 & -2.18 & 2.74 & & \\
\hline
\end{tabular}

$* *=p<0.01, *=p<0.05$, one-tailed tests. Coefficients are standardized. Values below the coefficients are t-values. Dependent variables are the number of lobby registrations by organizations in 1997.

The measures of the independent variables are discussed in the text. 